\title{
DIGITAL MORTGAGE BANKING ACCEPTABILITY IN PHILIPPINE UNIVERSAL BANKS: EVIDENCE FROM UTAUT MODEL
}

\author{
Dave T. Morales ${ }^{1}$ \\ PhD Student, University of Santo Tomas, Philippines. \\ (Email: dave_t_morales@yahoo.com) \\ Fernando L. Trinidad, Ph.D. ${ }^{2}$ \\ Professor, University of Santo Tomas, Philippines. \\ (Email: andongtrini@gmail.com)
}

Received date: 01-10-2019

Revised date: 20-10-2019

Accepted date: 04-11-2019

Published date: 10-12-2019

To cite this document: Morales, D. T., \& Trinidad, F. L. (2019). Digital Mortgage Banking Acceptability in Philippine Universal Banks: Evidence from UTAUT Model. Journal of Information System and Technology Management, 4(15), 01-15.

DOI: $10.35631 / \mathrm{jistm} .415001$

Abstract: The changing consumer behaviour all over the world has resulted in the shift of businesses into becoming client-centric. Clients nowadays want convenience, faster processes, seamless transactions, and instant service. The banking sector is not excused with these changes. In fact, bank clients want the same; bank services at the tip of their fingertips. So how should banks respond to these growing demands of clients? Involving technology in bank operations will ensure faster, more convenient, and more seamless transactions as this allows clients to access bank services anytime and anywhere. This study particularly paid attention to the digitization of mortgage banking using the UTAUT model to better understand its acceptability among its clients. The empirical results found that the determinants of behavioural intention to accept digital mortgage device among mortgage clients were facilitating conditions, performance expectancy and effort expectancy. Furthermore, results revealed that performance expectancy is directly related to internet time, frequency of product purchase using a mobile device and use of mobile banking.

Keywords: Banking, Digitization, Mortgage, Philippines, UTAUT Model

\section{Introduction}

It has been proven that banking is an integral part of our daily activities (Goyal, 2016). In fact, the banking industry for the longest time continues to act as the backbone of modern business (Akrani, 2011). But the increasing demands of customers across industries with 
regard to making business transactions more convenient has forced businesses all over the world to pay attention to technology driven operations. Banks, in particular, have invested in fintech to make their products and services more accessible to clients.

Since 2018, the banking industry is in a digital arms race in order to improve their digital banking capabilities in the front office alone. In fact, many retail banks have seen the importance of digitization.

In Asia, the financial and banking sector has experienced radical changes and upgrades in the last few years and is in a constant condition of advancement. Digitization has brought the banking industry new plans of action; advancement of ideas and areas of changes; and internet banking to monetary exchanges. These new uses in the financial sector require the bank leaders to know about the rapidly changing workplace and the general condition of progress within the mortgage loans division. Today, digitization is changing the banking business.

The banking industry had entered into a rather dramatic era, as digital disruption has forced many incumbent banks to step out of their comfort zone and up their digital game. The rapid change in customer behaviour, increasing expectations, omnichannel experience and the digitization of business and society, in general, have brought along what some people call the digital arms race in banking. Banks around the world are realizing how investments in digital technologies could benefit customer acquisition and satisfaction (Zigurat Innovation and Business School, 2019).

The signal of increasing use of technology in changing consumer behaviour is everywhere in Asia, and more specifically in the Philippines. One of the recent changes that is shaping the banking industry is that the consumer decision process has become increasingly multichannel (Chen et al., 2014).

While mortgage digitization is happening in many Asian countries, Philippine mortgage industry still seems to be in the wait-and-see mode. It is unclear why Philippine banks are not yet digitizing their current mortgage processes following the footsteps or other bank leaders in Asia despite its numerous advantages. The Philippine mortgage banking industry will need to invest in digital offerings and technologies to improve the loan origination process and the customer experience. In order to plan for such bank mortgage digitization, the acceptance of this technology must be first explored.

\section{Significance of the Study}

This study explored the mortgage clients' acceptance of bank's digital mortgage service which can provide important insights to understand technology acceptance better and to provide new ways to enhance technology acceptance. This study hopefully would benefit the following stakeholders:

\section{Bank leaders}

This will be useful in banking industry and leaders to analyze the current dynamic business arena with the introduction of digital technologies in mortgage service. Presently, the industry 
calls for constant and effective innovative strategies, business models and products to survive the competition and maintain an edge over others. This might contribute to the banking industry in the Philippines by addressing the issue about the impact of technological advancement, specifically mortgage digitization on mortgage clients' acceptance of the said technology.

\section{Bank Management and/or Executives}

Bank management and/or executives can benefit from the findings that will be gained from this study because important predictors of the bank's digital mortgage service acceptance will be identified. These determinants can be used as a business tool to enhance management and/or executive's decisions in fully embracing mortgage digitization. This will likewise identify the relationship of the determinants of the bank's digital mortgage service acceptance for successful implementation.

\section{Mortgage Customers/ Clients}

The study will be beneficial to the mortgage customers/clients, as the information that will be extracted from the results will be useful in identifying the areas or factors that should be improved and addressed in order to achieve clients' acceptance of the bank's digital mortgage service.

\section{Fintech Providers and Other IT Vendor Companies}

FinTech providers and other IT vendor companies can benefit from this study since this study might provide essential information about future online user behaviour to enable them to develop more functional mortgage software or system that would meet potential user expectations.

\section{Researchers}

This study will be helpful to future researchers since findings from this study will encourage them to use the results as basis for future research. The results of this study can serve as basis for further study on behavioural intention to integrate digital technology in mortgage banking. This could also serve as a valuable reference material to students and other researchers conducting similar studies.

\section{Scope and Limitations of the Study}

This study investigated the behavioural intentions to accept digital mortgage service from the perspectives of mortgage clients covering five leading universal banks in the Philippines which implement partial mortgage digitization process. The research design was a mixed method approach combining both quantitative and qualitative methodologies using survey research technique and interviews. The participants of this study were 25 executives and 250 bank clients.

The conceptual framework of the study was heavily grounded on UTAUT model of Venkatesh et al. (2003). This study aims to develop a model based on unified theory of acceptance and use of technology (UTAUT) to provide empirical proof that would support the acceptance of the bank's digital mortgage service among mortgage clients. 
The study areas covered five leading Universal Banks offering housing loans in the Philippines. These are BDO Unibank Inc. (BDO), Bank of the Philippine Islands (BPI), Security Bank Corp., Union Bank of the Philippines and East West Banking Corporation. These selected banks belong to the Top 15 universal banks ranked by the Bangko Sentral ng Pilipinas (BSP) according to their total assets as of March 31, 2018. The rankings and assets are as follows: BDO ranked as number one with a total asset of $\mathrm{P} 2,556,307.23$; BPI ranked as number three with a total asset of P1, 649,267.36; Security Bank ranked as number six with a total asset of P703, 319.61; Union Bank of the Philippines ranked as number nine with a total asset of P 547, 357.25; and East West Banking Corporation ranked as number twelve with a total asset of P301, 766.13.

Because digital mortgage is not yet fully implemented in the banking sector in the Philippines and still in its formative stage with low capability awareness among mortgage clients, the likelihood exists that possible biases can be present.

\section{Definition of Terms}

To assist the readers in understanding the use of the terms in this study, the following conceptual and operational definitions are provided:

Behavioral Intention refers to the behavioural decisions of mortgage clients to accept digital mortgage technology in processing and approval of home loans.

Digital Mortgage Service refers to the capability to provide a borrower experience, from initial online application to closing and funding, without human intervention on the part of the lender. With a digital mortgage, borrowers are able to apply for a mortgage online and track progress of the loan on any Internet-enabled device. The self-service aspect of the digital mortgage relies on technical innovation that automates much of the process.

Effort Expectancy is the degree of ease associated with the use of the system (Venkatesh et al., 2003). In this study, this refers to the amount of effort the mortgage clients must expend for the use of the bank's digital mortgage service.

Facilitating Conditions is defined as the degree to which an individual believes that an organizational and technical infrastructure exists to support use of the system. In this study, this is the mortgage client's belief that the bank has organizational support and technical infrastructure for full adoption of digital mortgage service.

Mortgage Digitization is the investment of the mortgage banking industry in digital offerings and technologies to improve the loan origination process and the customer experience.

Mortgage is a long-term loan secured by the collateral of some specified real estate property. In other words, it is an agreement that the property will be sold by the lender if the debt is not paid by the borrower through a series of payments as agreed. 
Performance Expectancy is the degree to which an individual believes that using a particular system would improve his or her job performance (Venkatesh et al., 2003). In the present study, this is defined as the degree to which bank's mortgage clients believe that digitization of mortgage service will assist them in improving the mortgage service and processes.

Social Influence is the degree to which an individual perceives that others believe he or she should use a particular system (Venkatesh et al., 2003). In the current study, this is the construct that refers to the degree to which the respondent perceives that important others believe they should use the bank's digital mortgage service. This construct is based upon the idea that the respondents' behavior is influenced by the way in which they believe others will see them as a result of their using the bank's digital mortgage service.

The Unified Theory of Acceptance and Use of Technology (UTAUT Model) is a synthesized conceptual model of technology use that contains four constructs that affect behavioral intention towards system use (Venkatesh et al., 2003). In this study, system use is the acceptance and use of the bank's digital mortgage service.

Universal Bank is a financial service conglomerate combining retail, wholesale and investment banking services under one roof and reaping synergies between them.

\section{Research Problem}

This study tested the relationship between facilitating conditions, performance expectancy effort expectancy, and social influence as independent variables and behavioural intentions to accept digital mortgage service as the dependent variable. The findings of this study can be valuable to banking industry and bank leaders to plan and effectively deliver mortgage services using digital technologies.

\section{Related Literature}

\section{Online Banking}

The development of Internet banking, branchless banks, and ATMs and also automated advances in data preparing, credit scoring, and mechanized guaranteeing have restricted the opportunity and requirement for individual communications with loan officers. A few specialists recommend that mechanical changes have empowered moneylenders to make 80 percent or a greater amount of their loaning choices without the inclusion of an advance office (Holmes, et al, 2007).

Cost savings are an essential driver behind the development of web usefulness and basic piece of the home loan application process. A similar Mortgage Focus found that web can give critical cost savings to the home loan originator. Organization and client appropriation of new innovations ordinarily develops in tandem- as more organizations offer online assets. Clients have turned out to be progressively acclimated with looking for mortgages on the web (Malm, 2005). 
The cost-adequacy of tasks on the Web empowers money related administration firms to utilize Web innovation to supplant or generously diminish the requirement for individual cooperation in the arrangement of their administrations. Online banking is characterized as access to the managing an account procedure by means of an Internet entrance established by a physical bank, through which clients can use services as savings facilities, money administrations, and investment. Thusly, banks that utilize their sites just to unveil data, and don't offer any web based online banking, are barred from the money saving benefits of virtual interactions.

As a rule, online banking benefits incorporate those of other self-benefit advancements, such as phone management of an account and programmed teller machines. The effect and scope of the administrations and elements of Internet banking services are much more significant than those that customary self-benefit innovation can offer. Distinctive Internet banking services today may incorporate the capacity to refresh account articulations, adding to reserve funds, making installments, applying for credits, putting resources into common subsidizes, applying and paying for mortgage, exchanging assets and so on. Furthermore, Internet managing an account empowers shoppers to tweak their keeping money benefits more than is conceivable with conventional self-benefit saving money innovation. Be that as it may, on the grounds that misrepresentation, information security and individual protection are altogether seen dangers required with utilizing Internet saving money, buyers regularly request more data about the online administrations than they do about customary self-benefit innovation (Chiou \& Sen, 2012).

The way that the market economy remakes the social economy is, in part, through the concept of the network. In the early decades of the 20th century, the language of technological networks was articulated with banking in publications such as The Wall Street Journal and The Economist. The result of this articulation was the creation of a model of social relations in which connections and flows define the fundamental base of community relations. While it may seem strange today given the prominence of technologically influenced ideologies about connectivity and freedom, in historical discourse the term network has almost uniformly been used to describe restrictive structures. In particular, when used in social or political contexts a network was understood as that which would be against the ideals of classical liberalism (Bolmer, 2011).

Internet is significantly different from former communications systems in that it is based on open standards. Previous data advanced profits in the 1990's, especially with the advent of Enterprise Resource Planning (ERP). There have been internal examinations. The development of commerce through the Internet (electronic commerce) is expected to have a significant impact on existing economic structures, and to stimulating the appearance of new markets. Electronic commerce facilitates not only business-to-business relations, but also sales by companies to consumers, and even transactions between consumers. In fact, the appearance and success of online auction Internet sites exemplifies this last point. With ebusiness, the advantages are not just from automating an organization's own particular internal procedures, rather advantages result from its capacity to spread productivity additions to the business processes of its providers and clients. E-business is about business procedure 
and infers a level of receptiveness and straightforwardness that is new to most business associations (Reixach, 2001).

The web offers a potential upper hand for banks and this preferred standpoint rests in the zones of cost decrease and more fulfillment of client needs. Urging clients to utilize the Internet for saving money exchanges can bring about impressive working costs savings. The web is the least expensive appropriation channel for institutionalized banking activities, for example, account administration or assets exchange. Client disappointment with branch keeping money in light of long lining and poor client benefit is a critical purpose behind the quick development to electronic conveyance. The dedication of senior administration is a main thrust in the appropriation and abuse of innovation. The effect of data innovation on the saving money industry and broke down both hypothetically and exactly how data related spending can influence bank benefits by means of rivalry in budgetary administrations that are offered by the banks (Mwangi \& Ngum, 2013).

Technological capabilities are available to transform the client experience, but they have not yet been developed into off-the-shelf, end-to-end solutions. It is an ideal time for mortgage institutions to create a distinctive way of interacting with their customers, differentiate themselves from their competitors, while also making their internal operations more efficient and adaptable to changing regulation. With the appropriate use of technology, a satisfying experience for consumers doesn't have to be incompatible with reduced costs, accelerated processing, and improved compliance. The winners in the current environment will be the ones that leverage technology to work both sides of the equation, both with the consumerfacing and with internal operations - to differentiate from competitors (Wyman, 2017).

\section{Mortgage Digitization}

Digitalization can be characterized as the utilization of advanced technology with a specific end goal to make new plans of action and to give new income and esteem bringing lead-ins. It is the way toward moving into an advanced business and the incorporation of computerized advances into regular daily existence (Gartner, 2016).

There are numerous advantages of mortgage digitization. According to Cognizant Consulting (2018), mortgage digitization would allow lenders to further automate compliance processes and eliminate manual interference. Second, competing on only products and services is no longer sufficient; customers will pay more for a better experience and for mortgage industry, digitization is crucial to that experience. In addition, younger generations often prefer digital technology as a self-service tool to meet their needs. Third, digitization can improve asset quality since a fully digitized mortgage process permits an expanded automation of underwriting, processing, closing, and quality assurance capabilities. Eventually, the improvements that can be realized through digitization and the benefits to compliance, customer experience, asset quality, and efficiencies lead to a more streamlined, faster, and less expensive mortgage process.

An efficient housing finance system has significant importance both in meeting the housing needs of individuals and in reinforcing the development of the construction, finance and other related sectors of an economy. Today, developed countries have advanced housing finance 
systems in which funds flow from savers to home-buyers by the mortgage markets. On the other hand, despite its recognized economic and social importance, housing finance often remains under-developed in developing countries mainly due to the lack of macroeconomic stability.

\section{Mortgage Loan}

A mortgage loan ranks among one of the oldest bank products. Involved may be a property that itself is subject to financing, or (other) properties. The mortgaged property may be owned by the mortgage loan (ML) applicant or another person, e.g. a family member. In the past century mortgage loans concerned primarily capital project financing. Such investments related to business activities and catering for housing needs. Over the course of history, several different methods of mortgage financing have evolved in developed economies (Múčková \& Hrnčiarová, 2010).

A fundamental question about mortgage markets - and markets in general — is whether the classic economic assumptions of rationality hold. If consumers are capable of making rational assessments of financial risk, then providing them with more information about the terms of their mortgage contract and what might happen under various scenarios will lead them to make to better decisions (Scanlon, Lunde, \& Whitehead, 2011).

A proficient housing framework has critical significance both in meeting the lodging needs of people and in fortifying the advancement of the development, back and other related parts of an economy. Worldwide experience proposes that, the broad accessibility of private home loans has positive effect on neediness mitigation, nature of lodging, foundation, and urbanization (Erbaş and Nothaft, 2005).

Money related and other conduct experts routinely figure corporate profit, money streams, loan costs, expansion rates, trade rates, stock costs, product costs, GDPs, and numerous other monetary and budgetary factors. In making such expectations, inside and master data with respect to the factors being considered would be very important (Ray, 2006).

Mortgage decisions have important consequences for consumers, lenders, and the state of the economy. Mortgage decisions are also prototypical of consumer financial choices that involve a stream of expenditures and consumption occurring across time (Atlas, Johnson \& Payne, 2017).

Today, developed countries have advanced housing finance systems in which funds flow from people with fund surpluses to the ones that are in need of them by the aid of mortgage markets. On the other hand, despite its recognized economic and social importance, housing finance often remains (Çobandağ, 2010).

\section{Unified Theory of Acceptance and Use of Technology}

The UTAUT model theorizes that four variables (performance expectancy, effort expectancy, social influence, and facilitating conditions) are direct determinants of the behavioral intention of technology use. Behavioral intention and facilitating conditions are direct determinants of use behavior. The model also incorporates four moderating factors (gender, 
age, experience, and voluntariness of use), each of which may have influence on the four primary constructs.

Several researches were made using the UTAUT model as its theoretical framework. These researches however revealed different results.

Tarhini, et al. (2014), in their study in Lebanon, revealed that performance expectancy (PE), social influence, PC and TTF are found to be significant predictors in influencing customers' behavioral intention (BI) to use internet banking and explained 61 per cent of its variance, with PE was found the strongest antecedent of behavior intention. Contrary to the UTAUT, the effect of effort expectancy on behavior intention was insignificant.

Additionally, Sarfaraz (2017) found that performance expectancy and effort expectancy significantly influence user's intention to adopt mobile banking services. However, no significant relations could be established for social influence. A study conducted in Pakistan by Raza et al. (2019) has corroborated the findings of Sarfaraz. The study found that the performance expectancy, facilitating conditions, effort expectancy have positive effects on mobile banking acceptance among Islamic banks in Pakistan, while social influence has no significant effect.

Bhatiasevi (2015) found that performance expectancy, effort expectancy, social influence, and behavioral intention to use mobile banking posited a positive relationship. Contrary to previous studies, the hypotheses testing perceived that facilitating conditions in the adoption of mobile banking were not supported.

While the studies made by Tarhini et al. (2014), Raza et al. (2019), Sarfaraz (2107) and Bhatiasevi (2015) did not fully accept the UTAUT model due to one or two factors not significantly affecting behavioural intentions, two studies found the UTAUT model's four (4) constructs to be significantly related to behavioural intentions.

Savić, J. \& Pešterac, A. (2018) revealed that the results of empirical research indicate that all components of the UTAUT model have statistically significant influence on intention to use mobile banking, with performance expectancy singled out as the most important antecedent, while effort expectancy has the weakest impact. In conformity, Gharaibh (2017) found that the adoption of mobile banking is positively and significantly influenced by the effort expectancy, performance expectancy, facilitating conditions, and social influence.

\section{Methodology}

This research reviewed the existing literature on Unified Theory of Acceptance and Use of Technology UTAUT model as applied in the banking industry. This study was limited to review and research articles and did not include book series, book, chapter in book, and conference proceeding. The articles were downloaded from scholarly sources in the field of social sciences, technology, business, and humanities using keywords such as UTAUT model, banking, financial technology, and digitization. These journals were synthesized, summarized, and presented in this paper in a tabular form. 
For the quantitative part of the study, a survey questionnaire, which was subjected for validity and reliability tests, was used to gather the data from 250 mortgage clients who are current or prospective users of digital mortgage service. This study used the UTAUT model as the theoretical basis which was evaluated using a sequence of quantitative data and analysis.

\section{Results and Discussion}

Table 1 shows the mortgage clients profile which were used as the moderating variables for this study. Overall, the sample was identified as either male or female composed of individuals over 40 years old with college degree.

A relatively equal gender distribution of mortgage clients participated in the surveys with males slightly higher $(n=126,50.4 \%)$ than females $(n=124,49.6 \%)$. The age distribution showed that most of them belonged to the oldest age groups of 51 years and older $(\mathrm{n}=89$, $35.6 \%)$ and 41 to 50 years $(n=83,33.2 \%)$, respectively. Only few respondents belonged to $31-40$ age group $(n=43,17.2 \%)$ and $21-30$ age group $(n=35,14 \%)$. Majority of the respondents were college graduates $(\mathrm{n}=171,68.4 \%)$. The remaining respondents completed high school $(n=41,16.4 \%)$, had post-graduate degree $(n=34,13.6 \%)$ and had high school education or lower $(n=4,1.6 \%)$, respectively. Data indicate that a typical bank mortgage client could either be female or male, more than 40 years of age with a college degree.

Table 1: Profile of the Mortgage-Client Respondents

\begin{tabular}{lcc}
\hline \multicolumn{1}{c}{ Profile } & $\begin{array}{c}\text { Frequency } \\
(\mathbf{n = 2 5 0})\end{array}$ & Percent \\
\hline Gender & & \\
$\quad$ male & 126 & 50.4 \\
female & 124 & 49.6 \\
& & \\
Age (in years) & & \\
21- 30 & 35 & 14.0 \\
31-40 & 43 & 17.2 \\
41- 50 & 83 & 33.2 \\
51 or older & 89 & 35.6 \\
& & \\
Education & & \\
High school or below & 4.0 & 1.6 \\
HS Diploma & 41 & 16.4 \\
College / Bachelor's degree & 171 & 68.4 \\
Post-graduate degree & 34 & 13.6 \\
\hline
\end{tabular}

The technology experience of the respondents was measured using four indicators, namely: computer knowledge, internet knowledge, internet experience and experience in online shopping and banking as summarized in Table 2 .

Most of the respondents rated themselves to have advanced $(\mathrm{n}=119,47.6 \%)$ to expert $(\mathrm{n}=$ $73,29.2 \%$ ) computer knowledge. The remaining respondents rated their computer knowledge 
as intermediate $(\mathrm{n}=44,17.6 \%)$, novice $(\mathrm{n}=6,2.4 \%)$ and fundamental $(\mathrm{n}=4,1.6 \%)$. In terms of internet knowledge, majority considered themselves to have advanced $(\mathrm{n}=128,51.2 \%)$ to expert $(\mathrm{n}=68,27.2 \%)$ knowledge of the internet. Other respondents rated their internet knowledge as intermediate $(n=44,17.6 \%)$, novice $(n=6,2.4 \%)$, and fundamental $(n=4$, $1.6 \%)$.

Majority of the respondents $(n=223,89.2 \%)$ have more than 3 years of experience using the internet. Only few of them have 1 to 3 years $(n=17,6.8 \%)$ and less than a year $(n=6,2.4 \%)$ of experience in using the internet. However, there were four respondents $(1.6 \%)$ who do not use the internet. As regards to the respondents' experience in online shopping and banking, most of the respondents have purchased product via mobile device $(n=187,74.8 \%)$, used internet banking $(\mathrm{n}=185,74 \%)$, and used mobile banking $(\mathrm{n}=190,76 \%)$.

This profile suggests that the sample of the study brings individuals who are prepared for the use of various technologies. This also allows us to infer that this group is accustomed to online shopping and banking services.

Table 2: Technology Experience of the Respondents

\begin{tabular}{|c|c|c|}
\hline Indicator of Technology Experience & $\begin{array}{l}\text { Frequency } \\
(\mathbf{n}=\mathbf{2 5 0})\end{array}$ & Percent \\
\hline \multicolumn{3}{|l|}{ Computer knowledge } \\
\hline $\begin{array}{l}\text { 1- Fundamental (basic computer } \\
\text { knowledge) }\end{array}$ & 4 & 1.6 \\
\hline 2 - Novice (limited computer experience) & 9 & 3.6 \\
\hline $\begin{array}{l}3 \text { - Intermediate (practical application of } \\
\text { computer) }\end{array}$ & 45 & 18.0 \\
\hline $\begin{array}{l}4 \text { - Advanced (extensive application of } \\
\text { computer } \mathrm{t} \text { ) }\end{array}$ & 119 & 47.6 \\
\hline $\begin{array}{l}5 \text { - Expert (recognized authority in } \\
\text { computer) }\end{array}$ & 73 & 29.2 \\
\hline \multicolumn{3}{|l|}{ Internet knowledge } \\
\hline 1- Fundamental (basic internet knowledge) & 4 & 1.6 \\
\hline 2 - Novice (limited internet experience) & 6 & 2.4 \\
\hline 3 - Intermediate (practical use of internet) & 44 & 17.6 \\
\hline $\begin{array}{l}4 \text { - Advanced (extensive use of internet } \\
\text { applications) }\end{array}$ & 128 & 51.2 \\
\hline $\begin{array}{l}5 \text { - Expert (recognized authority in internet } \\
\text { applications) }\end{array}$ & 68 & 27.2 \\
\hline \multicolumn{3}{|l|}{ Internet experience } \\
\hline None & 4 & 1.6 \\
\hline Less than a year & 6 & 2.4 \\
\hline $1-3$ years & 17 & 6.8 \\
\hline more than 3 years & 223 & 89.2 \\
\hline
\end{tabular}


Experience in online transactions / shopping

a) Purchase product via mobile device
$0=$ no
63
25.2
$1=$ yes

$\begin{array}{lll}0=\text { no } & 65 & 26.0 \\ 1=\text { yes } & 185 & 74.0\end{array}$
$0=$ no
60
24.0
$1=$ yes
190
76.0

b) Use of internet banking

c) Use of mobile banking

Table 3 presents the respondents' behavioral intention to accept the bank's digital mortgage service. It can be inferred that $50 \%$ of the respondents agreed, while 38.8 percent agreed on the statements that measured their acceptance to bank's digital mortgage service technology in processing and approval of home loans. On the other hand, the results showed that the respondents $(9.6 \%)$ disagreed and strongly disagreed $(1.6 \%)$ on the indicators of behavioral intention to accept the bank's digital mortgage service.

\section{Table 3: Behavioural Intention of the Respondents to Bank's Digital Mortgage Service} Acceptance

\begin{tabular}{|l|c|c|}
\hline \multicolumn{1}{|c|}{ Behavioural Intention } & $\begin{array}{c}\text { Frequency } \\
(\mathbf{n = 2 5 0})\end{array}$ & Percent \\
\hline strongly disagree & 4 & 1.6 \\
\hline disagree & 24 & 9.6 \\
\hline agree & 125 & 50.0 \\
\hline strongly agree & 97 & 38.8 \\
\hline
\end{tabular}

Table 4 presents the determinants of behavioural intention to accept digital mortgage service. The results revealed that the overall model accounts for $75.2 \%$ of the variance in behavioural intention to accept digital mortgage service. Additionally, the full model is significant ( $\mathrm{F}=$ $186.173, \mathrm{p}=.001$ ) and all the variables contribute significantly to the multiple regression (at $\mathrm{p}$ $=0.05$ ) except the variable social influence (SI) which does not relate significantly to the dependent variable $(\mathrm{p}=.575)$ when controlling for the other three predictors.

Table 4: Determinants of Behavioural Intention to Accept Digital Mortgage Service

\begin{tabular}{|c|c|c|c|c|}
\hline & $\begin{array}{c}\text { Unstandardized } \\
\text { Coefficients }\end{array}$ & $\begin{array}{c}\text { Standardized } \\
\text { Coefficients }\end{array}$ & $\begin{array}{l}\text { Sig. } \\
\text { (p) }\end{array}$ & \\
\hline & B & Beta & & VIF \\
\hline (Constant) & .011 & & .926 & \\
\hline performance expectancy & .400 & .393 & .001 & 3.061 \\
\hline effort expectancy & .150 & .145 & .010 & 3.089 \\
\hline social influence & .021 & .025 & .575 & 2.030 \\
\hline facilitating conditions & .425 & .400 & .001 & 2.289 \\
\hline \multicolumn{5}{|c|}{ Dependent Variable: behavioral intention } \\
\hline
\end{tabular}


$\mathrm{R}^{2}=.752 ; F=186.173, \mathrm{p}=.001$

The results of regression analysis showed that performance expectancy (PE), effort expectancy (EF) and facilitating conditions (FC) were significant predictors of behavioral intention (BI) at $5 \%$ level of significance.

The results led to the acceptance of the following assumptions: PE positively affects behavioral intention of the respondents to accept digital mortgage service; EE positively affects behavioral intention of the respondents to accept digital mortgage service; and FC positively affects behavioral intention of the respondents to accept digital mortgage service.

Meanwhile, the assumption that SI positively affects behavioral intention of the respondents to accept digital mortgage service was rejected.

\section{Conclusion}

The following conclusions were drawn based on the results of the study:

The determinants of behavioural intention to accept digital mortgage device among mortgage clients were facilitating conditions, performance expectancy and effort expectancy.

Based on the standardized beta coefficients, facilitating conditions (0.405), performance expectancy (0.383) and effort expectancy (0.134) had significant influence on bank mortgage clients' behavioural intentions to accept digital mortgage service.

It is conclusive that performance expectancy, effort expectancy and facilitating conditions affect behavioural intention to accept digital mortgage service.

Behavioral intention of clients to accept digital mortgage service is not influenced by others as shown in the tested hypothetical relationship between social influence and behavioral intention.

\section{References}

Akrani, G. (2011). What is a bank? Introduction, definition and features of bank. Retrieved 16 December 2016

Atlas, S. E., Johnson, E. J., \& Payne, J. W. (2017). Time preferences and mortgage choice. Journal of Marketing Research, 54(3), 415-429. doi: https://doi.org/10.1509/jmr.14.0481

Bhatiasevi, V. (2015). An extended UTAUT model to explain the adoption of mobile banking. Information Development. https://doi.org/10.1177/0266666915570764

Bolmer, D. G. (2011). Community as a financial network: Mortgages, citizenship, and connectivity. Democratic Communiqué, 39-57.

Chen, J., Durairaj, S., Vinayak, H. V., \& Lam, K. (2014). Digital banking in Asia: Are you ready for your next generation of customers? Retrieved from https://www.mckinsey.com/ /media/mckinsey/business\%20functions/mckinsey\%20di gital/pdf/2014\%20digital\%20banking\%20in\%20asia\%20-

$\% 20$ winning $\% 20$ approaches $\% 20 \mathrm{in} \% 20 \mathrm{a} \% 20$ new $\% 20$ generation $\% 20 \mathrm{of} \% 20$ financial $\%$ 20services.ashx 
Chiou, J.-S., \& Sen, C.-C. (2012). The antecedents of online financial service adoptation: the impact of physical banking services on internet banking acceptance. Behaviour and information technology, 859-871.

Çobandağ, M. (2010). Mortgage System and the Adaptation of Mortgage system in Turkey: Analyzing the Housing Loans.

Cognizant Consulting. (2018 September). The path ahead for mortgage digitization. Cognizant 20-20 Insights. from https://www.cognizant.com/whitepapers/the-path-ahead-for-mortgage-digitisationcodex3796.pdf

Erbas, N. S. \& Nothaft, F. (2005). Mortgage markets in Middle East and North African countries: Market development, poverty reduction, and growth. Journal of Housing Economics. 14(3):212-241

Gharaibeh, M. K., Arshad, M. R. M. \& Gharaibeh, N. K. (2018). Using the UTAUT2 Model to Determine Factors Affecting Adoption of Mobile Banking Services: A Qualitative Approach. International Journal of Interactive Mobile Technologies. 12 (4).

Goyal, R. (2016). AllBankingSolutions.com -. AllBankingSolutions.com. Retrieved 16 December 2016, from http://www.allbankingsolutions.com

Holmes, J., Isham, J., Petersen, R., \& Sommers, P. M. (2007). Does Relationship Lending Still Matter in the Consumer Banking Sector? Evidence from the Automobile Loan Market. Social Science Quarterly (Wiley-Blackwell)., 585-597.

https://www.gartner.com

Malm, E. (2005). Using Transaction-Specific Incentives. Journal of Website Promotion., 93103.

Múčková, V., \& Hrnčiarová, L. (2010). Mortgage in Banking Development in the Slovak Republic. Housing Finance International, 20-31.

Mwangi \& Ngum P. (2013). Effect of Baking Innovations on Financial Performance of Commercial Banks in Kenya.

Ray, R. (2006). Prediction markets and financial wisdom of crowds. The IJournal of Behavioral Finance, 1-4.

Raza, S., Shah, N. and Ali, M. (2019), "Acceptance of mobile banking in Islamic banks: evidence from modified UTAUT model", Journal of Islamic Marketing, Vol. 10 No. 1, pp. 357-376. https://doi.org/10.1108/JIMA-04-2017-0038

Reixach, A. A. (2001). The Effects of Information and communication Technologies on the Banking Sector and the Payment System.

Sarfaraz, J. (2017). Unified Theory of Acceptance and Use Technology (UTAUT) ModelMobile Banking. Journal of Internet Banking and Commerce. 22 (3)

Savic, J., \& Pesterac, A. (2018). Antecedents of Mobile Banking: UTAUT Model. The European Journal of Modern Economics. 16 (1), 20-29.

Scanlon, K., Lunde, J., \& Whitehead, C. (2011). Responding to the housing and financial crises. International Journal of Housing Policy, 23-49.

Tarhini, A., El-Masri, M., Ali, M. and Serrano, A. (2016), "Extending the UTAUT model to understand the customers' acceptance and use of internet banking in Lebanon", Information Technology \& People, Vol. 29 No. 4, pp. 830-849. https://doi.org/10.1108/ITP-02-2014-0034

Venkatesh, V., Morris, M. G., Davis, G. B., \& Davis, F. D. (2003). User acceptance of information technology: Toward a unified view. MIS quarterly, 27(3), 425-478. 
Wyman, O. (2017). A new age in mortgage. Marsh \& McLennn Companies.

Zigurat Innovation and Business School (2019) 